\title{
Milovan Djilas
}

El dia 20 d'abril de 1995 mor Milovan Djilas ads vuitanta-tres anys. Fa quasi quaranta anys, Djilas va anticipar els riscs i perills d'autoritarisme i totalitarisme que podien sorgir dels règims comunistes que es consoliden a Europa oriental després de la Segona Guerra Mundial. Autor marxista i militant comunista, publica diverses obres en el marc teòrico-conceptual marxista, lluita contra l'ocupació del seu pais pels nazis i contra els col.laboracionistes serbis i croates. Actua políticament en coherència amb la seva ideologia i col-labora amb Tito, líder comunista de la nova Iugoslàvia dels anys quaranta a forjar el socialisme autogestionari que defuig tota mena de totalitarisme i dependència de la progressivament potent Unió Soviètica. Ben aviat, cap a l'any 1948, denuncia el règim stalinista $i$, seguint a Tito o inspirant-lo, provoca la primera ruptura ideològica i política en el moviment comunista internacional. Cap a la meitat de la dècada dels cinquanta es distancia del seu amic i correligionari Tito, en defensar la liberalització econòmica i política per fer front a les necessitats del complex pais que era la Iugoslàvia. L'any de la revolta hongaresa contra el govern titella de la Unió Soviètica, el 1956, dóna suport als rebels.

Totes aquestes manifestacions $\mathrm{i}$ actuacions públiques el duen momentàniament a la presó $\mathrm{i}$ irreversiblement a la marginació politica i social a l'interior del seu propi país. No deixa però d'escriure criticant l'stalinisme o compilant una important trilogia sobre la Segona Guerra Mundial als Balcans, que té avui dia un clar caràcter premonitori. És en aquest moment, l'any 1965, quan es publica a Gran Bretanya el seu llibre més significariu i conegut: The New Class, escrit i publicat originàriament el 1957.

Djilas reconeix que la il.lusió socialista que la destrucció de la propietat capitalista dels mitjans de producció comportaria la desaparició de les classes, tal com varen predir els reòrics i líders marxistes-leninistes, no es fa realitat, quan el 1936 Stalin promulga una nova constitució per a la Unió Soviètica, anunciant que la classe explotadora s'havia extingit. Tot i esser això cert, una nova classe s'erigeix com a potencialment explotadora. Es tracta de la burocràcia política. Igual que històricament ha succeit amb l'aparició d'altres classes socials (la burgesia, per exemple) la nova classe es consolida en poder $\mathrm{i}$ influència a través d'un procés revolucionari de destrucció de l'ordre social precedent. Ara be, obtenen poder $\mathrm{i}$ influència un cop han imposat una nova forma econòmica de produir, per mitjà de la qual modelen un nou tipus de societat (la capitalista-burgesa). Com a classe social, diu Djilas, la nova classe es diferencia de les historicament conegudes perquè es forma i es consolida a partir del poder que li dóna el fet de pertànyer a una organització política (un partit polític) més que no pas perquè formi part de la vida econòmica i social.

El partit polític, d'origen bolxevic o, en general, proletari, és la base i el nucli de la nova classe. El partit polític forma la nova classe social però aques- 
ta classe acaba utilitzant l'organització o la institució política per créixer i consolidar-se. A mesura que la nova classe pren força, disminueix el paper del partit polític. Des de la perspectiva marxiana es produeix una perversio en el procés històric de formació de les classes socials. Generalment, els partits polítics són un producte de les classes socials i representen llurs interessos.

Segons Milovan Djilas, l'origen majoritàriament proletari de la nova classe es dilueix en la pràctica burocràtica propia d'una organització política i n'esdevé un estrat, però la nova classe no perd el contacte amb la classe obrera (i els camperols) sense la qual no es possible dur a terme el procés d'industrialització tan crucial als anys trenta i quaranta del nostre segle per a la Unió Soviètica. En aquest moment, la nova classe representa encara els interessos dels obrers i camperols, dels pobres i desvalguts que desitgen sortir d'una situació històrica d'extrema precarietat econòmica. És així com, en nom de la classe obrera, s'estableix progressivament el monopoli, en principi intel.lectual $\mathrm{i}$ ideològic, més tard polític, de la nova classe sobre el conjunt de la societat. Primer es recolza en l'avanguarda del proletariat; més endavant, en el conjunt del proletariat del qual emergeix. Heus ací com es tanca el cercle: els fills de la classe obrera esdevenen els membres més convençuts i dogmàtics de la nova classe, en gestionar i administrar els recursos materials i no materials de la societat. Així doncs, de la històricament classe social explotada i oprimida, en sorgeix la nova classe explotadora i dominant.

A més de la gran categoria humana i intel.lectual d'una figura del pensament social del nostre segle com Milovan Djilas, aquest autor és, al meu entendre, crucial per analitzar les arrels d'un dels debats més apassionants entre teòrics marxistes occidentals del final dels anys setanta. La polèmica sobre la burocràcia com a nova classe dominant (Paul Sweezy) o un cancer en una societat de transició del capitalisme al socialisme (Ernest Mandel), s'enceta cap als anys 1978-1979. Per a Sweezy, la burocràcia soviètica s'ha erigit en cinquanta anys en la classe dominant que controla l'aparell de l'Estat. Els obrers no participen en les decisions de l'organizzació econòmica i política, ni en les qüiestions que afecten directament les seves vides. Els buròcrates actuen suplint el proletariat. Conformen un grup social privilegiar que rep la seva força $i$ legitimació a través del partir polític únic, que en la mesura en què s'autoreprodueix, impulsa la continuïtat de la burocràcia com a classe dominant.

Mandel considera, al contrari, que la capacitat d'autoreproducció de la burocràcia es limita als beneficis i béns que comporta poder conservar un càrrec, peró l'aparició de la burocràcia no comporta un canvi en la forma de produir ni, conseqüentment, una transformació en les relacions socials de producció, que permetin definir-la com a classe social. Tampoc no ha fet variar la forma d'apropiació del producte social excedent en un país corn l'antiga Unió Soviètica.

Malgrat els canvis pregons en les societats de socialisme real, després de la caiguda del mur de Berlín, l'any 1989; malgrat l'existència d'altres veus sociològiques (Wladzimierzi Wesolowski, Stanislav Ossowski, de l'Escola de Varsòvia), contemporànies de Djilas, analitzant críticament el problema del poder i el 
control, la relació entre intel.liguèntsia i burocràcia, etc., en una societat en la qual, teòricament, es tendia cap a la despararició de la desigualtat i les classes socials, Milovan Djilas s'ha de reivindicar com a autor pioner en el tractament de temes bàsics per a la nostra disciplina (la igualtat, "'estructura social) i com a intel-lectual capaç d'unir el pensament crític amb el compromís polític de forma coherent $i$ conseqüent. 